\title{
Veneno ou defensivo? Uma análise do discurso acerca do Projeto de Lei que visa à mudança na regulamentação do uso de agrotóxicos no Brasil
}

\section{POISON OR DEFENSIVE? AN ANALYSIS OF THE DISCOURSE ABOUT THE BILL AIMED} AT CHANGING THE REGULATION OF PESTICIDE USE IN BRAZIL

\section{Lara Cristina Vollmer ${ }^{l}$}

ORCID: http://orcid.org/0000-0002-4944-621X

(Escola Superior de Propaganda e Marketing, Programa de Pós-Graduação em Comunicação e Práticas de Consumo da ESPM-SP. São Paulo - SP, Brasil).

\section{Marcia Perencin Tondato ${ }^{2}$}

ORCID: http://orcid.org/0000-0002-1277-7517

(Escola Superior de Propaganda e Marketing, Programa de Pós-Graduação em Comunicação e Práticas de Consumo da ESPM-SP. São Paulo - SP, Brasil).

\section{Resumo}

Este artigo apresenta uma análise dos discursos que envolvem o Projeto de Lei 6.299/2002 apresentado pela Frente Parlamentar Agropecuária (FPA) e rejeitado por um diverso grupo de instituições. $\mathrm{O}$ objetivo é compreender a natureza argumentativa dos dois principais polos ideológicos envolvidos nesta questão e extrair os sentidos produzidos nas narrativas, utilizando para isso a Análise do Discurso (ADF) de linha francesa, e recorrendo aos estudos de linguagem e palavra desenvolvidos por Baccega, Bakhtin, Orlandi e Schaff, entre outros autores.

Palavras-chave: Comunicação e consumo. Análise do discurso. Agrotóxico. Projeto de Lei 6.299/2002.

\section{Abstract}

This article presents an analysis of the speeches that involve the Bill $6.299 / 2002$ presented by the Parliamentary Front of Agriculture (FPA) and rejected by a diverse group of institutions. The objective is to understand the argumentative nature of the two main ideological poles involved in this issue and to extract the meanings produced in the narratives, using the French Discourse Analysis, as well as language and word studies developed by Baccega, Bakhtin, Orlandi and Schaff, among other authors.

Keywords: Communication and consumption. Discourse analysis. Pesticide. Projeto de Lei $6.299 / 2002$. 


\section{Introdução}

Após quinze anos de tramitação no Congresso Nacional, o Projeto de Lei 6.299/2002 (MAGGI, 2018) que visa à alteração na regulamentação de registro, uso e fiscalização de agrotóxicos no Brasil ressurge na pauta da Câmara dos Deputados com muita polêmica e debate. Com relatoria da Frente Parlamentar Agropecuária (FPA) - mais conhecida como "bancada ruralista" -, o projeto de autoria do então senador licenciado e hoje ministro da Agricultura Blairo Maggi (PP-MT) foi apresentado pelo deputado Luiz Nishimori (PRPR) em 16 de maio de 2018, em defesa de dezoito propostas que englobam desde a redução de tempo para registro e comercialização dos produtos junto aos órgãos de saúde e meio ambiente, até a mudança do termo oficial para estes, que passariam a denominar-se “defensivos fitossanitários" ou "defensivos de controle ambiental".

Dentre os órgãos e instituições favoráveis às alterações propostas estão grupos ligados ao agronegócio, como a Empresa Brasileira de Pesquisa Agropecuária (Embrapa, vinculada ao Ministério da Agricultura, Pecuária e Abastecimento), a Confederação da Agricultura e Pecuária do Brasil (CNA), além das Associações de Produtores de Soja (Aprosoja), milho (Abramilho) e algodão (Abrapa). Estas últimas criaram o site "Lei do Alimento Mais Seguro", cujo objetivo é divulgar a necessidade da aprovação desta lei aos demais parlamentares e público em geral.

Do outro lado deste embate e defendendo a rejeição desse projeto, estão: o Instituto Nacional do Câncer (INCA), o Ministério Público Federal (MPF), a Fundação Oswaldo Cruz (Fiocruz), a Agência Nacional de Vigilância Sanitária (Anvisa) entre outros nomes de peso que compõem um grupo de 329 instituições e ONGs que assinam o "Manifesto contra o Pacote do Veneno". Tal documento se ancorava no site do movimento "Chega de Agrotóxicos", cujo objetivo é informar ao público sobre suas convicções e convidar seus visitantes a assinarem uma petição a favor da aprovação de outro Projeto de Lei (PL 6670/2016), que institui a Política Nacional de Redução de Agrotóxicos (PNaRA).

Um duelo de narrativas envolve o debate que aqui analisamos confrontando algumas das orientações discursivas apresentadas pelos dois lados da questão, com o objetivo de melhor compreender "os mecanismos que promovem convencimento e

${ }^{1}$ Disponível em: http://www.leidoalimentomaisseguro.com.br/. Acesso em: 09 set. 2018.

2 Em 2018 o "Manifesto contra o Pacote do Veneno" se ancorava no site do movimento "Chega de Agrotóxicos", mas recentemente verificou-se que agora dispõe de site próprio em campanha permanente. Disponível em: https://contraosagrotoxicos.org/manifesto-contra-o-pacote-do-veneno/. Acesso em: 30 ago. 2019.

3 Disponível em: http://www.chegadeagrotoxicos.org.br/. Acesso em: 12 set. 2018. 
persuasão, entre outros jogos argumentativos de linguagem que visam à veracidade do enunciador" (BACCEGA, 1989). O embate discursivo, cuja força maior se estabelece por meio da linguagem e, portanto, da força das palavras empregadas nos discursos, fica evidente quando entendemos os interesses por trás de cada construção parafrásica. Para Foucault (1996, p.10), "por mais que o discurso seja aparentemente bem pouca coisa, as interdições que o atingem revelam logo, rapidamente, sua ligação com o desejo e com o poder".

Para esta análise, portanto, focaremos nos sites de informação apresentados pelos dois grupos de interesse: "Lei do Alimento Mais Seguro" versus "Manifesto contra o Pacote do Veneno" e "Chega de Agrotóxicos", para o que recorreremos também a outras fontes de informação e legislações que possam nos ajudar na ancoragem deste estudo.

\section{Cultura: historicidade e linguagem}

Tendo como fundamental a questão do sentido, a Análise de Discurso se constitui no espaço em que a Linguística tem a ver com a Filosofia e com as Ciências Sociais. Em outras palavras, na perspectiva discursiva da Linguagem é linguagem porque faz sentido. E a linguagem só faz sentido porque se inscreve na história (ORLANDI, 2010, p. 25).

O "universo cultural" (enunciação) e as "variantes linguísticas do enunciador" (regionais, sociais, situacionais) são importantes para a Análise de Discurso, mas se faz necessário compreender esta trama do ponto de vista histórico e político a partir das mudanças sociais dos indivíduos que a constroem ao longo do tempo, de forma que possamos analisar com mais consistência as produções de sentido que nascem dos embates discursivos que ocorrem na atualidade. Baccega (1995) nos alerta sobre a influência dos avanços científicos, que "impregnam as palavras de novos sentidos", apontando que é no cotidiano - ao que Bakhtin (1988) chama de "ideologia do cotidiano" - que podemos intuir essas mudanças sociais e o nascimento dos novos sentidos: "o novo está contido nas possibilidades do velho, e esse fato pode ser percebido na própria linguagem" (BACCEGA, 1995, p. 32-35). É observando e analisando as práticas sociais que podemos perceber os desvios de comportamento e as incoerências em relação ao sistema posto (leis, ideologia etc.).

Antes de iniciarmos a análise do corpus propriamente dita, é importante compreendermos a origem da palavra chave deste embate: agrotóxico. No Brasil, este 
termo passou a ser utilizado para denominar produtos agrícolas utilizados nas lavouras, justamente para evidenciar sua toxidade ao meio ambiente e à saúde pública. Sua inserção legal se deu em 1989 pela Lei Federal no 7.802 de 11 de julho, regulamentada pelo Decreto 98.816 e, posteriormente, pelo Decreto $n^{\circ} 4.074$, de 4 de janeiro de 2002, no seu artigo $1^{\circ}$, inciso IV, que relata:

IV - agrotóxicos e afins - produtos e agentes de processos físicos, químicos ou biológicos, destinados ao uso nos setores de produção, no armazenamento e beneficiamento de produtos agrícolas, nas pastagens, na proteção de florestas, nativas ou plantadas, e de outros ecossistemas e de ambientes urbanos, hídricos e industriais, cuja finalidade seja alterar a composição da flora ou da fauna, a fim de preservá-las da ação danosa de seres vivos considerados nocivos, bem como as substâncias e produtos empregados como desfolhantes, dessecantes, estimuladores e inibidores de crescimento (BRASIL, 2002).

O termo parece bem definido no decreto que o relaciona só e diretamente aos produtos agrícolas, pastagens, florestas e demais ecossistemas. Não menciona os seres humanos senão por meio da ideia de toxidade que o termo carrega em si. A palavra “agrotóxico", enquanto signo que carrega em si a prática social já solidificada, apresentase de forma explícita ao grande público que facilmente "lê" o conjunto das suas partes: "agro" (campo ou terra cultivada ou que é boa para a lavoura) e "tóxico" (que ou o que envenena; que tem a propriedade de envenenar; venenoso; que ou o que produz efeitos nocivos no organismo; qualquer produto químico, como herbicidas, inseticidas e fungicidas usado para melhorar a qualidade e a produção da lavoura; defensivo agrícola). A terminação "cida", contida nas palavras que definem o termo tóxico (herbicidas, inseticidas e fungicidas), advém do latim caederes (ação de matar), e parece estar bem consciente na memória relacional dos indivíduos, que a associam diretamente às palavras de mesma analogia com a "morte", tais como suicídio e homicídio. Por outro lado, toda e qualquer definição encontrada relaciona o termo com defesa e proteção, no caso, das lavouras, plantas e alimentos.

O termo "agrotóxico", sem dúvida, leva o enunciatário a entender que se trata de algo que mata, ou que defende e protege, e que, portanto, exige que se tenha muito cuidado com seu manuseio e/ou utilização.

Em um glossário da área do agronegócio, o termo "agrotóxico" é identificado como "termo de conotação negativa" (SCHÜTZ; KANOMATA, 2014), enquanto que em glossário referente à proposta da oposição, a definição do termo vai além da breve definição, assemelhando-se mais a um alerta: 
Substância química de uso agrícola, doméstico ou em saúde pública que tem por objetivo matar insetos, fungos, ou plantas que foram considerados indesejados. O manejo agrícola com base em agrotóxicos busca atacar os sintomas - insetos, fungos e plantas indesejadas - ao invés de buscar corrigir o desequilíbrio ecológico que ocasionou o surgimento destes elementos indesejados.

Seu objetivo é sempre matar a vida, razão pela qual deveriam ser chamados de biocidas. Termos como "Defensivo Agrícola", "Defensivo Fitossanitário" ou "Remédio" são erroneamente utilizados como sinônimos de agrotóxicos, pois escondem os riscos destas substâncias.

O contato com agrotóxicos pode causar intoxicações agudas e intoxicações crônicas (GLOSSÁRIO, [200-?]).

Schaff (1971) entende a linguagem como uma unidade verbal e mental que exerce papel ativo na sociedade, cuja existência é condição necessária para a construção do pensamento conceitual e que, portanto, "é um reflexo específico da realidade [...], a criadora de nossa imagem do mundo" (SCHAFF, 1971, p.254). Para Bakhtin (1988, p. 34) a palavra constitui um "fenômeno ideológico por excelência", por se tratar do indicador mais sensível das transformações sociais, e sua realidade é absorvida pela função de signo. Disso inferimos que o pensamento conceitual é resultado da linguagem instituída a partir da cultura e, portanto, também da história, e seus significados ideológicos podem ser encontrados nos discursos e interdiscursos da realidade cotidiana, como observamos neste estudo. Cabe ainda ressaltar a importância da mídia nesse processo de construção de significados.

A questão colocada em pauta pelo Projeto de Lei 6.299/2002 vem sendo discutida há pelo menos três décadas, mas seus entraves demonstram ser mais antigos que o próprio termo aqui referido. O Brasil ainda apresenta uma estrutura colonial no que se refere à questão agrária, muito embora tenha vivenciado um complexo e profundo processo de crescimento econômico nesse sentido. Desde os tempos de colonização portuguesa não houve mudanças substanciais no que diz respeito à propriedade fundiária no país:

AEuropa Ocidental e países como os Estados Unidos (Homestead Act de 1862), China (o Grande Salto para Frente, de 1959) e URSS (a partir da Revolução de 1917) em algum momento, e de diferentes formas, promoveram o maciço acesso da população à terra, e mesmo vizinhos latino-americanos, como a Argentina, forjaram sociedades mais abertas no que se refere à propriedade da terra (vide as políticas de colonização do território implementadas no século XIX) do que a brasileira (NAKATANI, 2012, p. 214). 
Além da herança colonialista no que diz respeito à questão agrária são evidentes as influências de uma cultura escravagista, estruturalmente enraizada, e do modelo capitalista adotado desde sempre para a constituição de uma sociedade caracterizada pela concentração desigual de riquezas e recursos. Essas características, ao longo dos anos, contribuíram consideravelmente, entre outros aspectos, para uma polarização política que, invariavelmente, apresenta-se de forma desfavorável ao bem comum.

Quando os discursos e interdiscursos a serem analisados estão inseridos diretamente na política que rege uma determinada sociedade - como é o caso da análise que segue -, as questões ideológicas nos parecem mais afloradas, senão impudentes. Em um nível mais abrangente, podemos perceber as relações diretas e indiretas que os dois polos têm em relação ao objeto em questão, seja pelas influências decorrentes de seus meios (história e cultura), ou pelos interesses diretamente relacionados às suas existências (ideológicos ou financeiros).

Assim, procedemos à análise com vistas a melhor entender o que está por trás dessa produção de sentidos. Para tanto, em um primeiro momento de análise consideramos que olhar para os estereótipos envolvidos nessa trama seja o melhor caminho em busca desse entendimento.

\section{Estereótipo: representações e estigmas}

Todo enunciado retoma e responde necessariamente à palavra do outro, que está inscrito nele; ele se constrói sobre o já-dito e o já-pensado que ele modula e, eventualmente, transforma. Mais ainda, o locutor não pode se comunicar com os seus alocutários, e agir sobre eles, sem se apoiar em estereótipos, representações coletivas familiares e crenças partilhadas (CHARAUDEAU; MAINGUENEAU, 2008, p. 216).

O conceito de estereótipo é demarcado pela imaginação coletiva e geralmente é mais pessimista do que otimista, gerando, frequentemente, certa hostilidade e vontade de oposição. É, portanto, um elemento de linguagem construído, imaginário e social que, quando analisado, também nos revela uma carga política, motivo pelo qual iniciamos nosso "olhar" por esse prisma.

Charaudeau e Maingueneau (2008) definem estereótipo como sendo "uma cristalização no nível do pensamento ou no da expressão". Segundo os autores, para a Análise do Discurso esta representação coletiva cristalizada é uma construção de "leitura", 
considerando que ela emerge justamente quando há uma recuperação dos elementos espalhados e seccionados em função de um modelo cultural já existente e que depende do balanço interpretativo do analista, bem como de sua bagagem de conhecimento. Segundo Maingueneau (2001) deve haver uma liberdade para formulações próprias e posições particulares por parte dos analistas de discurso, acrescentando que a "fidelidade teórica" não deve implicar na submissão à teoria.

Walter Lippmann (1972) faz suas ponderações a respeito dos estereótipos nos mostrando que a opinião pública é construída a partir das reações dos seres humanos a um mundo percebido ou desenhado em suas mentes.

Dizem-nos tudo sobre o mundo antes que o vejamos. Imaginamos a maioria das coisas antes de experimentá-las. E a menos que a educação nos tenha tornado agudamente conscientes, essas preconcepções governam profundamente todo o processo de percepção (LIPPMANN, 1972, p. 156).

O cerne das reflexões de Lippmann sobre os estereótipos é que cada ser humano, com sua infinita ignorância e limitado saber, é levado a tomar decisões sobre inúmeras questões, muitas delas bastante complexas, sobre as quais não possui suficiente entendimento, o que o inflige a interpretá-las a partir de seu restrito ponto de vista, revelando assim um retrato muitas vezes injusto ou ingênuo a respeito dos outros e do mundo em que vive.

Baccega (1998) nos mostra que o estereótipo transporta discriminações, gera exclusões e carrega em si preconceitos e pré-juízos negativos que condicionam a rejeição e intolerância entre as pessoas. Assim como Lippmann (1972), a autora sugere que estes sentimentos, em sua grande maioria, são passados de geração a geração sem que sejam percebidos. Nesse sentido, analisamos aqui os dois lados da discussão sobre o Projeto de Lei 6.299/2002, sem considerar as questões políticas referentes, em busca de um melhor entendimento dos estereótipos envolvidos nos discursos dentro de seus movimentos e organizações ao longo da história.

De um lado, Blairo Maggi ${ }^{4}$ e a bancada ruralista - a maior do Congresso Nacional

\footnotetext{
4 Blairo Borges Maggi, conhecido por seus opositores como o "Rei da Soja", é engenheiro agrônomo, empresário e político brasileiro. Já foi governador de Mato Grosso (2003- 2007, reeleito para 2007-2010) e, atualmente, é o ministro da Agricultura, Pecuária e Abastecimento. Iniciou sua carreira política no Partido Popular Socialista (PPS), mas transitou pelo Partido da República (PR) quando reeleito governador de MS, época em que o Greenpeace o elegeu o rei do desmatamento e lhe concedeu o prêmio "Motosserra de Ouro". Embora tenha apoiado o PT em muitos momentos da política nacional, foi a favor do Impeachment de Dilma Rousseff, momento em que se filiou ao Partido Progressista (PP) para compor o governo de Michel Temer. Blairo Maggi chegou a entrar para a lista de bilionários da revista Forbes, e vem sendo sistematicamente investigado por pagamento de propinas, desvio de dinheiro público, corrupção ativa e tentativa de obstrução da justiça, entre outras denúncias.
} 
- constituem uma frente parlamentar diretamente ligada ao agronegócio e que são, em sua maioria, proprietários de terras cujos interesses são imanentes à questão aqui colocada.

A pesquisadora da USP Sandra Helena G. Costa pesquisou a vida de 374 deputados e senadores para fazer a tese "Questão agrária e a bancada ruralista no Congresso Nacional". Inclusive com o histórico familiar e a participação na política brasileira na formação das oligarquias regionais. Sem contar 23 que não têm nenhum imóvel registrado ou qualquer ligação empresarial com o agronegócio, os restantes 351 declaram possuir 863.646,53 hectares. Os dados foram consultados nos arquivos do TSE e no cadastro do INCRA.

Já o jornalista Alceu Castilho, autor do livro "Partido da Terra", que levantou 13 mil declarações de bens de políticos brasileiros, incluindo deputados estaduais, prefeitos, vices, suplentes, chegou a um número de 2,03 milhões de hectares. As informações registradas pela Justiça Eleitoral são declarações dos próprios candidatos. Mas o que interessa, além das prioridades da bancada ruralista, é que eles representam empresas e proprietários de terras no país, que movimentam $\mathrm{R} \$ 440$ bilhões entre a produção agrícola e pecuária. $\mathrm{O}$ capitalismo agrário brasileiro não é um negócio de famílias, embora elas continuem no poder em vários estados, comandando a máquina do Estado (TUBINO, 2013, p.1).

O termo "ruralista" é relativo às atividades rurais ou ao ruralismo, bem como aos proprietários de fazendas e a seus interesses econômicos e políticos, àquele que tem propriedade rural (de atividade agrícola, pecuária etc.), ou que defende os interesses dos proprietários rurais. Em suma, refere-se, de ampla forma, a todos os proprietários rurais do país.

O Movimento dos Trabalhadores Rurais Sem Terra (MST) $)^{5}$ tem sido o maior oponente dos proprietários rurais. Constituída na década de 1970-80 sob influência do marxismo e do cristianismo progressista (teologia da libertação), a militância do MST tem influenciado negativamente a imagem (pública) dos fazendeiros, acusados de deter muitas terras improdutivas, o que justificaria, entre outros argumentos, a luta pela reforma agrária. Os "fazendeiros", portanto, são tidos como ricos proprietários rurais - que não representam os pequenos e médios produtores -, e constituem uma imagem culturalmente sedimentada desde o período do Brasil colonial; são os “donos" de terras, que detém muitos recursos e riquezas, em detrimento daqueles que nada tem e que para eles trabalham (primeiro os escravos, depois imigrantes, mulheres e até crianças, constituindo um ${ }_{5}$ Disponível em: http://www.mst.org.br/quem-somos/. Acesso em: 20 set. 2018. 
contingente de mão de obra barata), que defendem apenas seus interesses econômicos, muitas vezes utilizando a máquina pública a seu favor.

Do outro lado do debate está um grupo bem mais heterogêneo que repudia veementemente o projeto de lei apresentado, composto por entidades ligadas às áreas da medicina e saúde pública; preservação do meio ambiente; agricultura orgânica, biodinâmica e alternativa; pequenos produtores rurais e moradores de pequenas comunidades; professores; defensores de direitos de minorias e tantas outras instituições representativas da sociedade civil, como a Anvisa (Agência Nacional de Vigilância Sanitária), o IDEC (Instituto Brasileiro de Defesa do Consumidor), a WWF (World Wide Foundation), o Greenpeace e o próprio MST. No total, são 329 organizações assinantes do "Manifesto contra o Pacote do Veneno". Tal diversidade impossibilita uma análise de estereótipo, entretanto, não nos impede de avaliar que este grupo de oposição - como é denominado pela mídia - oferece maior capacidade de representação justamente por sua diversidade e polifonia.

São muitos grupos, portanto, contra o que nos apresenta como um único grupo, que aqui estereotipamos nominal e ideologicamente como "fazendeiros".

\section{campo de batalha discursiva}

As formas de poder podem ser consolidadas por meio da linguagem. Para Bakhtin

[...] a linguagem não é utilizada apenas para transmitir informações, mas, e, sobretudo, para firmar interesses, estabelecer níveis de dominação, fazendo do mundo dos signos uma arena onde são travadas as mesmas batalhas encontradas no mundo dos homens (BAKHTIN, 1988, p. 132).

As reflexões que provocam conexões entre ideologia e signo, palavra e poder, linguagem e experiências culturais ganham força e sentido, e os mecanismos manipulatórios se constroem nas relações existentes entre palavras e mundo (BACCEGA; CITELLI, 1989), aspectos que nos movem na análise dos elementos de nosso interesse.

Como corpus desta análise, utilizamos os 10 tópicos que representam as "razões para apoiar", apresentadas pelo site "Lei do Alimento Mais Seguro", em contrapartida aos seis tópicos relacionados no "Manifesto Contra o Pacote do Veneno" e os sete motivos para assinar "\#ChegaDeAgrotoxicos", uma petição a favor de outro projeto, o PL 6670/2016 
que institui a Política Nacional de Redução de Agrotóxicos (PNaRA). Para facilitar e agilizar o entendimento desta análise, trataremos o primeiro grupo como "proponente" e o segundo como "oposição", termos que consideramos neutros na representação dos grupos, em vista de minimizar eventuais tendenciosidades de pontos de vista.

Apresentamos a análise de recortes dos discursos mencionados buscando demonstrar como mecanismos da linguagem atuam por meio da subjetividade que permeia o tema, entendendo-a a partir de Baccega:

[...] o universo de cada indivíduo é formado pelo diálogo desses discursos, nos quais seu cotidiano está inserido. É a partir dessa materialidade discursiva que se constitui a subjetividade. Logo, a subjetividade nada mais é que o resultado da polifonia que cada indivíduo carrega (BACCEGA In: BARROS FILHO; CASTRO, 2007, p. 79-80).

Os proponentes querem a extinção do termo agrotóxico, substituindo-o por produto fitossanitário (fito $=$ alvo, objetivo + sanitário $=$ relativo à saúde e higiene) ou de controle ambiental - termos que sinalizam um reposicionamento de um produto considerado tóxico e nocivo para algo referente à manutenção da saúde e higiene, alterando o entendimento de algo antes maléfico (tóxico às pragas e humanos) para um reconhecimento de um eventual efeito benéfico (salutar às plantas). Tal mudança não só acarreta um novo sentido (maléfico $>$ benéfico) como também muda seu alvo (pragas e humanos $>$ plantas), escamoteando o fator colateral mais perturbador apresentado pela oposição no que se refere aos produtos em questão, que é o dano à saúde das pessoas, tanto daquelas que trabalham no campo e estão em contato direto com tais produtos, quanto de quem consumirá os alimentos provenientes das plantações que sofreram a ação desses produtos e que, por isso, serão indiretamente afetadas por eles.

O grupo dos opositores alega que a alteração do termo - e, consequentemente, também de sentido -, escamotearia o verdadeiro risco decorrente do uso desses produtos, configurando o que podemos chamar de uma "verdade parcial". Ainda que essa transformação de sentido não implicasse em mudanças ideológicas de imediato, pois o termo agrotóxico veio se consolidando em nossa memória ao longo de muitos anos, existe a possibilidade da ocorrência de um "esquecimento enunciativo", a que Michel Pêcheux se refere: 
[...] o esquecimento número dois, que é o da ordem da enunciação, ao falarmos, o fazemos de uma maneira e não de outra, e, ao longo de nosso dizer, formam-se famílias parafrásticas que indicam que o dizer sempre podia ser outro. Ao falarmos "sem medo", por exemplo, podíamos dizer "com coragem", ou "livremente" etc. Isto significa em nosso dizer e nem sempre temos consciência disso. Este "esquecimento" produz em nós a impressão de realidade do pensamento. Esta impressão, que é denominada ilusão referencial, nos faz acreditar que há uma relação direta entre o pensamento, a linguagem e o mundo, de tal modo que pensamos que o que dizemos só pode ser dito com aquelas palavras e não com outras, que só pode ser assim (PÊCHEUX, 1975 apud ORLANDI, 2010, p. 35).

Ao nos depararmos com as "razões para apoiar" anunciadas pelo proponente, o primeiro item diz que "defensivos agrícolas são os remédios das plantas e servem para protegê-las contra pragas e doenças. Assim posto, relacionam os produtos em questão com remédios que protegem as plantas, ao invés de pesticidas que matam as pragas. Muda-se, portanto, o foco da ação do produto, que deixa de ter como função matar as pragas para tornar-se um remédio para as plantas, que agora carregam a condição de "doentes".

Os opositores alegam que muitos desses produtos são "sabidamente cancerígenos e causam danos no material genético, problemas reprodutivos e relacionados a hormônios e má formações fetais", e que, portanto, são venenos que matam ou, no mínimo prejudicam a saúde, mas agora se referem a outro sujeito: o ser humano. Ainda neste sentido, a oposição oferece dados da ONU (Organização das Nações Unidas) que diz serem os agrotóxicos responsáveis por "200 mil mortes por intoxicação aguda a cada ano", e aponta que "cerca de 90\% das mortes ocorreram em países em desenvolvimento" (NAÇÕES..., 2013, p.1). Tais dados, provenientes de estudos de uma organização respeitada e notória por seu trabalho pela paz e desenvolvimento mundial, indicam uma preocupação que vai além dos interesses específicos do proponente e da oposição, atesta a importância e cuidado com que o assunto deve ser tratado.

No segundo item, os proponentes afirmam que "o PL vai incentivar a produção nacional de defensivos agrícolas", recorrendo a argumentos que implicam no desenvolvimento do país, apelando, portanto, ao sentimento de patriotismo dos enunciatários. Para a oposição, o projeto visa apenas restringir os registros dos produtos no Ministério da Agricultura, bem como tirar competências de estados e municípios, com consequências que "ameaçam diretamente a soberania alimentar, tornando nossa 
agricultura dependente das empresas transnacionais que dominam este mercado". As interpretações sobre as consequências da alteração dos termos pelos dois lados, proponente e oposição, mostram-nos claramente as possibilidades de um posicionamento ideológico, o primeiro dizendo que irá incentivar e produzir, o outro que irá restringir, retirar competências e tornar nossa agricultura dependente de empresas transnacionais, produzindo sentidos opostos e determinando os lugares de fala dos sujeitos nesse cenário. Ou seja, não há discurso sem sujeito, e não há sujeito sem ideologia (ORLANDI, 2010, p. 47).

É importante compreendermos as relações interdiscursivas dos enunciados para entendermos melhor suas origens e complexidades. Para Pêcheux (2011), as formações discursivas são informações relacionadas diretamente com as formações ideológicas. Em uma determinada formação social é possível identificar um modo de produção específico que as domina e um estado de relações de classe que as conforma. As práticas sociais vigentes, a partir dos aparelhos estatais, são a forma concreta por meio das quais essas relações de classe se expressam. Tais relações dão espaço a posições de classe específicas, que não constituem indivíduos, mas configuram formações que mantêm, entre si, relações de antagonismo, aliança ou dominação (PÊCHEUX, 2011).

Podemos, assim, inferir algumas ordens ideológicas de classe nos contextos aqui apresentados. No item 3, o proponente alega que "defensivos garantem a produção de comida em larga escala e com preço final mais baixo", utilizando-se de um argumento que recorre ao bolso do consumidor final. Para a oposição, as informações neste sentido se referem ao faturamento das grandes empresas vinculadas ao setor dos agrotóxicos, e comparam os valores mencionados a investimentos do governo na área de atendimento da população pelo serviço público: "Só em 2015, as empresas faturaram R \$32 bilhões com a venda de agrotóxicos, enquanto o Brasil investiu apenas $\mathrm{R} \$ 3,8$ bilhões em alimentação escolar". Os argumentos seguem o mesmo princípio, o apelo ao bolso do consumidor. Um menciona aberta e diretamente o lucro ao seu público final, outro se apresenta de forma indireta e exige um maior discernimento do prejuízo intrínseco deste contexto. $\mathrm{O}$ proponente alega que o lucro irá para o consumidor final, mas seu discurso releva uma posição neoliberal - ou ainda, de uma política mais de direita -, quando propõe a liberdade de mercado e uma restrição à intervenção estatal sobre esse mercado. Já a oposição dá a entender que quem lucra com a produção e comercialização dos agrotóxicos é a indústria química, e reforça seu argumento por meio de uma comparação entre os valores tangíveis disso com os benefícios intangíveis proporcionados à população trazendo para o discurso 
um aspecto ideológico: o baixo investimento na alimentação escolar. O segundo discurso apresenta um tom socialista - indicando um posicionamento político de esquerda, o que implica numa oposição ideológica extrema ao discurso do proponente ao lançar seu olhar e voz em defesa dos menos favorecidos (socioeconomicamente falando).

No item 4 de "razões para apoiar", o proponente alega que o projeto "vai zelar pela segurança dos alimentos, dos consumidores e do meio ambiente", e no item 6 diz que "vai trazer mais regras na aplicação dos defensivos agrícolas para proteger os trabalhadores". Zelo, segurança e proteção aos alimentos, consumidores, meio ambiente e trabalhadores são as promessas que o projeto anuncia, mas com as quais a oposição não concorda, pois "pode causar doenças", "atingem diretamente os camponeses e camponesas que produzem nossa comida", "contaminam cursos d'água, reservatórios e aquíferos", "matam a vida do solo", "ameaçam diretamente a soberania alimentar". Um discurso que explicita os sentidos absolutamente opostos aos do proponente e podem ganhar mais credibilidade por sua clareza e especificidade.

Outro elemento discursivo de efeito é o modo como cada grupo se refere aos indivíduos diretamente envolvidos: enquanto o proponente utiliza o termo "trabalhador", a oposição se refere a este público como "camponeses e camponesas". Trabalhador nos remete à atividade exercida (trabalho), camponês designa moradia, origem (campo). $\mathrm{O}$ trabalhador é aquele que trabalha, ao passo que o camponês é um indivíduo que mora no campo e de lá retira seu sustento com o trabalho na terra, antes mesmo de dizer que ele também exerce determinado trabalho, existe um contexto que o define, contexto esse que implica diretamente no espaço de utilização dos produtos em questão. Nestas definições, o trabalhador é posto como subordinado a um empregador, enquanto que o camponês é referido como pequeno proprietário de terra ou trabalhador rural, uma situação mais abrangente e aparentemente mais autônoma. Ao se referir a camponeses e camponesas, a oposição contempla ainda - e sem economia de palavras - o gênero feminino, tão presente no trabalho rural do país, explicitando reconhecimento às questões de gênero. Tal menção excede as expectativas e torna o discurso da oposição mais respeitoso e simpático, em especial as "menos favorecidas dos menos favorecidos" desta questão.

A análise da utilização dos termos trabalhador e camponês também nos revela os destinatários dos discursos: enquanto o proponente busca um diálogo com o empregador (seus pares políticos ou fazendeiros, indústria química, etc.), a oposição direciona seu discurso ao empregado. 
No item 7 de "razões para apoiar", o proponente cita que "os defensivos agrícolas garantem que os alimentos cresçam saudáveis", mas o discurso da oposição coloca como "mito a ideia de que pesticidas são vitais para garantir a segurança alimentar", e, mais uma vez, o sentido atribuído ao termo "saúde" é alterado: para o proponente a "saúde" é dirigida aos alimentos, enquanto que para a oposição é dirigida às pessoas que consomem estes alimentos.

Os itens 8 e 9 de "razões para apoiar" mencionam "mais tecnologia" chegando ao campo e se referem à nova lei como "uma lei tão moderna quanto os defensivos existentes", o que nos leva a crer que há um objetivo em atualizar e adiantar o assunto em pauta. Porém, a oposição alega que este Projeto de Lei em questão nos conduz a "diversos retrocessos", e atribui estes retrocessos a tudo o que historicamente foi construído ou conquistado até então e que não pode ser ignorado em detrimento da velocidade desejada: poderes de registro e veto da ANVISA e IBAMA, autonomia dos órgãos de saúde para publicação de dados de análise de agrotóxicos em alimentos e garantias na avaliação de substâncias cancerígenas entre outros tantos argumentos. A oposição também compara nossas práticas às de países do Primeiro Mundo: "Dos 50 venenos que mais utilizamos, 22 já são banidos na União Europeia, que também restringe práticas nocivas de aplicação como a pulverização aérea de agrotóxicos, ainda permitida no Brasil”. Tais argumentos colocam em xeque os objetivos de modernização mencionados na argumentação do proponente.

No nono item das "razões para apoiar", o proponente diz que a "Lei do Alimento Mais Seguro" promete contemplar a "agricultura familiar, que é negligenciada na lei atual". Para a oposição, a bancada ruralista atua "para defender os interesses da indústria agroquímica em detrimento do meio ambiente, da saúde pública e do apoio aos pequenos agricultores e à agroecologia". Ainda que discursivamente o apelo ao público composto pelos menos favorecidos se inverta, a interpretação do contexto nos mostra que, enquanto proponente se refere aos agricultores de pequeno porte como agricultura familiar - relativo a doméstico, feito em casa, caseiro -, a oposição atribui um sentido mais amplo ao mesmo público, a ele se referindo com mais propriedade: pequenos agricultores - menção ao porte, e não à tecnologia -, e agroecologia, que é o segmento da ecologia que busca a integração equilibrada entre atividades agrícolas e meio ambiente, ao que podemos nos referir como sendo uma tendência no setor da agricultura. 


\section{Considerações finais}

Observamos que as argumentações apresentadas pelos dois principais polos ideológicos envolvidos na questão da regulamentação de registro, uso e fiscalização de agrotóxicos acerca do Projeto de Lei apresentado pela Frente Parlamentar Agropecuária carregam sentidos ideológicos análogos, com direcionamento de seus discursos a diferentes públicos. Suas tendências e interesses se fazem presentes nos pequenos detalhes deste confronto de sentidos, sinalizando ao pesquisador as dinâmicas de vida social em que cada grupo se insere. Cada qual apresenta suas "meias verdades", em que aspectos políticos e simbólicos se confrontam e movimentam os sentidos das práticas discursivas mobilizadas, evidenciando suas diferentes naturezas, conforme mostramos no Quadro 1.

Quadro 1 - Síntese dos resultados da Análise de Discurso sobre o Projeto de Lei 6.299/2002.

\begin{tabular}{|c|c|c|}
\hline $\begin{array}{l}\text { Sobre o } \\
\text { Projeto de Lei 6.299/2002 }\end{array}$ & $\begin{array}{l}\text { PROPONENTE } \\
\text { (Lei do Alimento mais Seguro) }\end{array}$ & $\begin{array}{l}\text { OPOSIÇÃO } \\
\text { (Pacote do Veneno) }\end{array}$ \\
\hline Defendem o termo & produto fitossanitário & Agrotóxico \\
\hline A ação dos produtos é & defender e proteger & matar e fazer adoecer \\
\hline Relacionam os produtos com & Plantas & Pessoas \\
\hline Tal relação é & benéfica > proteção > saúde & maléfica $>$ risco $>$ morte \\
\hline Comparam os produtos com & remédios (salutar às plantas) & venenos (tóxicos às pessoas) \\
\hline $\mathrm{O}$ PL, em relação à produção & incentiva e aumenta a produção nacional & $\begin{array}{l}\text { torna-a dependente de empresas transna- } \\
\text { cionais }\end{array}$ \\
\hline Novas leis do PL promovem & maior autonomia & maiores riscos \\
\hline Novas leis do PL promovem & mais tecnologia & diversos retrocessos \\
\hline Lucro será de & consumidores finais (intangível) & empresas ligadas ao agronegócio (tangível) \\
\hline A natureza discursiva é & neoliberal / direita & socialista / esquerda \\
\hline Associações diretas ao PL & zelo, segurança e proteção & contaminação, matança e ameaça \\
\hline Os mais envolvidos são & trabalhadores, empregados por outros & camponeses(as), que produzem para nós \\
\hline No PL, segurança alimentar é & uma garantia & um mito \\
\hline Pequenos produtores rurais são & agricultura familiar > doméstico e caseiro & pequenos agricultores > relação ao porte \\
\hline Direciona o discurso para & o empregador e empresas/agronegócios & o empregado e um público mais geral \\
\hline Defende interesses da & classe dominante & classe trabalhadora / população em geral \\
\hline
\end{tabular}

Fonte: elaborado pelas autoras.

É evidente como a memória discursiva - ou interdiscursos, conforme Baccega nos 
ensina (2010) - sobre uma questão comum, no caso o Projeto de Lei 6.299/2002, apresentase por meio de distintos signos conforme as posições de cada um dos enunciadores, o proponente e a oposição, acionando produções discursivas tão peculiares aos meios e interesses relacionais de cada um.

O fato de que há um já-dito que sustenta a possibilidade mesma de todo dizer, é fundamental para se compreender o funcionamento do discurso, a sua relação com os sujeitos e com a ideologia. A observação do interdiscurso nos permite [...] remeter o dizer da faixa a toda uma filiação de dizeres, a uma memória, e a identificá-lo em sua historicidade, em sua significância, mostrando seus compromissos políticos e ideológicos (BACCEGA, 2010, p. 32).

Nesse sentido consideramos a possibilidade de atribuir ao proponente a condição de classe dominante, que procura se apropriar da linguagem em busca da promoção de uma certa alienação linguística. Desafiado a suscitar uma mudança de entendimento sobre o que é ou deixa de ser o agrotóxico, o proponente utiliza paráfrases que buscam mascarar a realidade intrínseca ao produto: a toxidade que gera riscos aos seres humanos e também $\grave{a}$ biodiversidade como um todo. $\mathrm{O}$ direcionamento do discurso aos seus pares, ou seja, a uma classe social e econômica composta por fazendeiros, grandes empresas ligadas ao agronegócio e uma ampla frente parlamentar, faz-nos entender que os interesses defendidos com o projeto não são exatamente aqueles que beneficiariam a maioria da população, embora sinalize preocupações nesse sentido. Um posicionamento discursivo que nos leva a inferir tratar-se de uma "luta com cartas marcadas", no contexto de uma sociedade capitalista, em um cenário de neoliberalismo.

Do outro lado da argumentação, no discurso da oposição, identificamos que sim, agrotóxico é defensivo, assim como é também veneno, dependendo do sentido que se pretende inferir ao enunciado. Mas é, sobretudo, qualquer coisa que precisa ter um bom entendimento por toda a população em sua complexa polissemia.

Na busca utópica por uma conciliação destes discursos, poderíamos dizer que agrotóxico é veneno que não deve matar ou fazer adoecer as pessoas, defensivo que combate as pragas e busca a proteção e saúde das lavouras sem prejudicar o meio ambiente - e, sobre este último, pouco se fala ainda em discursos, glossários e outros enunciados ligados ao tema.

Indo além nestas considerações finais, refletimos que a valorização da honestidade, o respeito, o compromisso com o outro e, acima de tudo, um maior comprometimento com 
a construção de um lugar melhor para todos ultrapassam a postura e ética dos governantes, espraiando-se pela conduta de todo um grupo que, em seu cotidiano, aprendeu e cultivou comportamentos individualistas e egocêntricos, que resultam hoje em uma impossibilidade de também reconhecer o potencial das consequências das decisões tomadas a respeito do trato do meio ambiente nos vários âmbitos de significação.

\section{Referências}

BACCEGA, Maria Aparecida; CITELLI, Adilson. Retórica da manipulação: os Sem-Terra nos jornais. Comunicação e Artes, São Paulo, v.14, n. 20, p. 23-29, 1989.

BACCEGA, Maria Aparecida. O estereótipo e as diversidades. Comunicação \& Educação, São Paulo, v. 13, p. 7-14, set./dez. 1998. Disponível em: http://www.revistas.usp.br/comueduc/article/ view/36820/39542. Acesso em: 18 set. 2018.

BACCEGA, Maria Aparecida. Comunicação e linguagem: discursos e ciência. São Paulo: Moderna, 1998.

BAKHTIN, Mikhail. Marxismo e filosofia da linguagem. São Paulo: Hucitec, 2009.

BARROS FILHO, Clovis de; CASTRO, Gisela (org.). Comunicação e Práticas de Consumo. São Paulo: Saraiva, 2007.

BRASIL. Decreto no ${ }^{\mathbf{4}} \mathbf{0 7 4}$ de 4 de janeiro de 2002. Regulamenta a Lei no 7.802 , de 11 de julho de 1989, que dispõe sobre a pesquisa, a experimentação, a produção, a embalagem e rotulagem, o transporte, o armazenamento, a comercialização, a propaganda comercial, a utilização, a importação, a exportação, o destino final dos resíduos e embalagens, o registro, a classificação, o controle, a inspeção e a fiscalização de agrotóxicos, seus componentes e afins, e dá outras providências. Brasília, DF: Presidência da República, [2002]. Disponível em: http://www. planalto.gov.br/ccivil_03/decreto/2002/d4074.htm. Acesso em: 18 set. 2019.

BOSI, Ecléa. Entre a opinião e o estereótipo. In: BOSI, Ecléa. O Tempo Vivo da Memória: ensaios de psicologia social. São Paulo: Ateliê Editorial, 2003.

CARVALHO, Miguel Mundstock Xavier de; NODARI, Eunice Sueli; NODARI, Rubens Onofre. "Defensivos" ou "agrotóxicos"? História do uso e da percepção dos agrotóxicos no estado de Santa Catarina, Brasil, 1950-2002. História, Ciências, Saúde - Manguinhos, Rio de Janeiro, v. 24, n. 1, p.75-91, jan-mar 2017. 
CHARAUDEAU, Patrick; MAINGUENEAU, Dominique. Dicionário de análise do discurso. 2. ed. São Paulo: Contexto, 2008.

COSTA, Sandra Helena Gonçalves. A questão agrária no Brasil e a bancada ruralista no Congresso Nacional. 2012. Dissertação (Mestrado em Geografia Humana) - Faculdade de Filosofia, Letras e Ciências Humanas, Universidade de São Paulo, São Paulo, 2012.

FIORIN, José Luiz. Linguagem e ideologia. 12. ed. São Paulo: Ática, 2006.

FOUCAULT, Michel. A ordem do discurso. São Paulo: Loyola, 1996.

GIDDENS, Anthony. As consequências da modernidade. Tradução Raul Fiker. São Paulo: UNESP, 1990.

GLOSSÁRIO. Agrotóxico Mata. [200-?]. Disponível em: http://contraosagrotoxicos.org/ glossario/. Acesso em: 30 ago. 2019.

GREGOLIN, Maria do Rosário. Sentido, sujeito e memória: com o que sonha nossa vã autoria? In: GREGOLIN, Maria do Rosário; BARONAS, Roberto (org.). Análise do discurso: as materialidades do sentido. São Carlos: Claraluz, 2003. p.47-58.

LIPPMANN, Walter. Estereótipos. In: STEINBERG, Charles. (org.). Meios de comunicação de massa. São Paulo: Cultrix, 1972.

MAGGI, Blairo. Projeto de Lei No 6.299, de 2002. Brasília, 2018. Disponível em: https://www. camara.leg.br/proposicoesWeb/prop_mostrarintegra?codteor $=1654426 \&$ filename $=$ TramitacaoPRL+1+PL629902+\%3D\%3E+PL+6299/2002. Acesso em: 20 set. 2019.

MAINGUENEAU, Dominique. Discurso, enunciado e texto. In: MAINGUENEAU, Dominique. Análise de textos de comunicação. São Paulo: Cortez, 2001.

NAÇÕES UNIDAS BRASIL. 10 mar. 2017. Disponível em: https://nacoesunidas.org/pesticidasmatam-200-mil-pessoas-por-intoxicacao-aguda-todo-ano-alertam-especialistas/. Acesso em: 19 set. 2018.

NAKATANI, Paulo. Histórico e os limites da reforma agrária na contemporaneidade brasileira. Serviço Social \& Sociedade, São Paulo, n. 110, 2012. 
ORLANDI, Eni Pulcinelli. Discurso: fato, dado, exterioridade. In: ORLANDI, Eni P.. Autoria, leitura e efeitos do trabalho simbólico. Campinas: Pontes, 2004.

ORLANDI, Eni Pulcinelli. Análise de discurso: princípios e procedimentos. Campinas: Pontes, 1999.

PÊCHEUX, Michel. Análise de discurso: Michel Pêcheux. Textos escolhidos por Eni Orlandi. Campinas: Pontes, 2011.

PÊCHEUX, Michel. Semântica e discurso: uma crítica à afirmação do óbvio. 2. ed.. Campinas: Unicamp, 1995.

PRETI, Dino. Sociolinguística: os níveis da fala. São Paulo: Nacional, 1982.

SCHAFF, Adam. Linguagem e realidade. In: SCHAFF, Adam. Linguagem e conhecimento. Coimbra: Almedina, 1974.

SCHÜTZ; KANOMATA. Agriculture - Agricultura: glossário de termos usados na agricultura. [s.l.] dez. 2014. Disponível em: http://www.sk.com.br/sk-agr.html. Acesso em: 21 set. 2018.

THOMPSON, John B. Ideologia e cultura moderna: teoria social crítica na era dos meios de comunicação de massa. Petrópolis: Vozes, 1995.

TUBINO, Najar. Bancada ruralista: tudo pela terra. Carta Maior, 13 out. 2013. Disponível em: https://www.cartamaior.com.br/?/Editoria/Politica/Bancada-ruralista--tudo-pela-terra/4/29182. Acesso em: 18 set. 2018.

1 Docente no Curso de Design Visual da ESPM-SP, Mestre e Doutoranda no Programa de PósGraduação em Comunicação e Práticas de Consumo da ESPM-SP. E-mail: lara@vollmer.com.br.

2 Doutora em Comunicação pela Escola de Comunicações e Artes da Universidade de São Paulo (2004), Mestre em Comunicação pela Universidade Metodista de São Paulo (1998). Graduada em Publicidade (1992) pela UMESP. Estágio de pós-doutoramento na Universidade de Brasília (2015). Docente titular do Programa de Pós-graduação em Comunicação e Consumo da Escola Superior de Propaganda e Marketing - ESPM-SP. E-mail: mtondato@espm.br. 